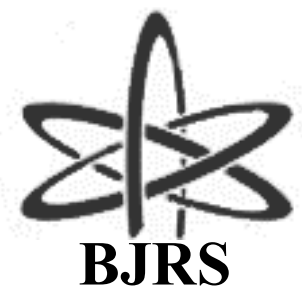

BRAZILIAN JOURNAL

$\mathrm{OF}$

RADIATION SCIENCES

08-01 (2020) 01-20

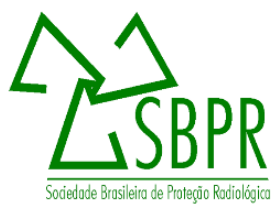

\title{
Aplicação do material gesso e da mistura gesso e barita como blindagem para baixas energias na área de
} radiodiagnóstico, nível mamografia.

\author{
Lins $^{\mathrm{a}}$ J. A. G., Limaa ${ }^{\mathrm{a}, \mathrm{b}, \mathrm{c}}$ F. R. A., dos $\operatorname{Santos}^{\mathrm{b}}$ M. A. P., Oliveira ${ }^{\mathrm{c}, \mathrm{d}}$ A.C.H., \\ Silva $^{\text {a }}$ V. H. F. F., Farias ${ }^{\mathrm{c}}$ W. A. W. A. \\ ${ }^{a}$ DEN/UFPE - Departamento de Energia Nuclear/Universidade Federal de Pernambuco, 50670-901, Recife-PE, Brasil \\ ${ }^{b}$ CRCN-NE - Centro Regional de Ciências Nucleares do Nordeste, 50730-120, Recife-PE, Brasil \\ ${ }^{c}$ LDN/IFPE - Laboratório de Dosimetria Numérica/Instituto Federal de Educação Ciência e Tecnologia de \\ Pernambuco, 50740-540, Recife-PE, Brasil \\ ${ }^{d}$ DEinfo/UFRPE - Departamento de Estatística e Informática/ Universidade Federal Rural de Pernambuco
}

jorgelins93@hotmail.com

\section{RESUMO}

Ao longo dos últimos anos, diversos materiais utilizados em alvenaria, tais como o chumbo, concreto, blocos cerâmicos e tijolo, têm sido estudados para utilização como blindagem contra as radiações ionizantes de diferentes energias em instalações radioativas. $\mathrm{Na}$ área de radiodiagnóstico, o chumbo e a barita são os materiais mais utilizados como blindagem, porém para feixes de radiação $X$ de baixa energia, como em mamografia $e$ odontologia, o material gesso pode ser empregado, como afirma o Conselho Nacional sobre Proteção Radiológica e Medidas (National Council on Radiation Protection \& Measurements) por meio do seu relatório de número 147 (NCRP Report $\mathrm{N}^{\circ}$ 147). Esse trabalho desenvolveu materiais de gesso e também de mistura gesso e barita com formatos de placas com área de 10 x 10 centímetros, tendo como objetivo caracterizar físico-quimicamente e verificar a viabilidade do uso desses materiais como blindagem contra a radiação $X$ de baixas energias, utilizando-se de feixes de raios $X$ mamográficos padronizados em laboratórios de metrologia. A partir da irradiação foi possível obter as curvas de transmissão, determinar as camadas semirredutoras (CSR) e decirredutoras (CDR), bem como adquirir os diferentes espectros para cada material. $O$ material de mistura gesso e barita teve uma melhor resposta de blindagem em relação ao material de gesso puro, contudo ambos podem ser considerados como bons atenuadores contra a radiação $X$ de baixas energias.

Palavras-chave: Gesso, Barita, Mistura, Blindagem, Qualidades de raios X. 


\begin{abstract}
Over the past few years, various materials used in masonry, such as lead, concrete, ceramic blocks and brick, have been studied for use as shielding against ionizing radiation from different energies in radioactive facilities. In the area of diagnostic radiology, lead and barite are the most used materials as shielding, but for bundles of low energy $X$ radiation, as in mammography and dentistry, plaster material can be used, as affirmed by the National Council on Radiological Protection and Measures through its report number 147 (NCRP Report N $^{\circ}$ 147). This work developed plaster phantoms as well as gypsum \& barite mixing with plate formats with a $10 \times 10$ centimeter area, aiming to characterize physico-chemically and verify the feasibility of using these materials as shielding against low-energy X-ray radiation, using mammographic X-ray bundles in metrology laboratories. From the irradiation, it was possible to obtain the transmissions curves, to discover the Half Value Layers (HVL) and the Tenth Value Layers (TVL), as well as to acquire the different spectra for each material. The gypsum \& barite mixing material had a better shielding response compared to pure gypsum material, however both can be considered as good attenuators against low energy $X$ radiation.
\end{abstract}

Keywords: Gypsum, Barite, Mixture, Shielding, Qualities of X-ray. 


\section{INTRODUÇÃO}

A radiologia diagnóstica está em evolução contínua, em resposta ao desenvolvimento tecnológico, permitindo diagnósticos com qualidade cada vez melhor [1]. Contudo, se faz necessário o estudo de materiais aplicados como barreiras de proteção, objetivando reduzir a intensidade das radiações ionizantes, além de aperfeiçoar o dimensionamento e aumentar o conhecimento das propriedades de atenuação para outros materiais.

O material gesso foi escolhido pois o presente estudo científico foi feito no estado de Pernambuco, onde está situado o Pólo Gesseiro do Araripe, no qual se tem a maior produção de gesso do Brasil e onde esse material pode ser encontrado com um grande percentual de pureza. Além do gesso puro, foi utilizada uma mistura de gesso com barita com o objetivo de se alcançar uma maior densidade do material irradiado, assim tendo-se uma melhor atenuação.

As medidas experimentais foram realizadas em laboratório de metrologia ao qual tinham qualidades de referência WMV implantadas (a nomenclatura WMV significa que o alvo do equipamento deve ser de tungstênio (W) com filtro de molibdênio (Mo) para feixes diretos (V)) qualidades de raios $\mathrm{X}$ que caracteriza feixes de mamografia, de acordo com os padrões do laboratório Alemão Physikalisch-Technische Bundesanstalt (PTB).

Deste modo, o estudo visou caracterizar dois tipos diferentes de materiais, o gesso e uma mistura de gesso e barita, usando-os como blindagem contra feixes de raios $\mathrm{X}$ de baixa energia na qualidade de referência WMV (feixes de mamografia). Sendo os objetivos específicos a serem alcançados: caracterizar fisica e quimicamente o material gesso e o material gesso e barita, irradiar os dois tipos de materiais em diferentes qualidades de mamografia, construir curvas de transmissão para o material gesso e mistura gesso e barita, obter e comparar as camadas semirredutora e decirredutora para cada tipo de material, obter e comparar os espectros para o material gesso e da mistura gesso e barita para a qualidade WMV 28 e WMV 35, otimizar: facilidade e tempo de construção da blindagem em relação a um bom material atenuador para baixas energias, agregado a um baixo custo financeiro e comparar o desempenho em relação a blindagem dos dois materiais usados. 


\section{MATERIAIS E MÉTODOS}

Este trabalho foi realizado em diferentes etapas e laboratórios. O primeiro passo foi fazer a confecção de dois tipos de placas, sendo feitas com material gesso e mistura de gesso com barita, após prontas foram realizas as suas caracterizações físicas e químicas e por último foram efetuadas as irradiações em laboratórios de metrologia.

\subsection{Confecção das placas de gesso}

A preparação das placas de gesso utilizadas como corpos de prova nos ensaios para blindagem dos raios X, foi realizada no Laboratório de Química e Ensaios do Gesso, localizado no Instituto de Tecnologia de Pernambuco - ITEP. O gesso utilizado foi o do tipo Beta sem aditivos e de origem regional (Pólo Gesseiro do Araripe), sendo cortados em forma de placas quadradas, cujas dimensões são de $10 \mathrm{~cm}$ x $10 \mathrm{~cm}$ e espessuras diferenciadas para que pudessem ser usadas livres ou combinadas entre si durante a irradiação.

Foram utilizados três diferentes espessuras de placas, sendo de $2,5 \mathrm{~mm}, 5 \mathrm{~mm}$ e $8 \mathrm{~mm}$. Para confecção das placas de gesso de espessuras $2,5 \mathrm{~mm}$ e $5 \mathrm{~mm}$ foi utilizado 280 gramas de gesso para 150 gramas de água. No caso da confecção das placas de gesso com espessura de $8 \mathrm{~mm}$, a quantidade de massa teve que ser aumentada, sendo utilizada 420 gramas de gesso para 225 gramas de água.

\subsection{Confecção das placas de mistura gesso e barita}

A confecção das placas de mistura gesso e barita foram realizadas no Centro Regional de Ciências Nucleares do Nordeste - CRCN-NE. A preparação das placas de gesso e barita misturadas foi executada obedecendo um traço com proporção de 1:1 dos materiais constituintes para que a placa conseguisse homogeneizar e não ficasse quebradiça, sendo 94,7 gramas para a barita e 45 gramas para o gesso e estes sendo misturados com $50 \mathrm{ml}$ de água. Cada mistura dessa equivaleu a preparação de duas placas gesso e barita, possuindo cada uma aproximadamente $2 \mathrm{~mm}$ e $5 \mathrm{~mm}$ de espessura. O processo de secagem da placa gesso e barita pode ser observado na Figura 1. Cada placa levou em média 24 horas para a sua total secagem. 


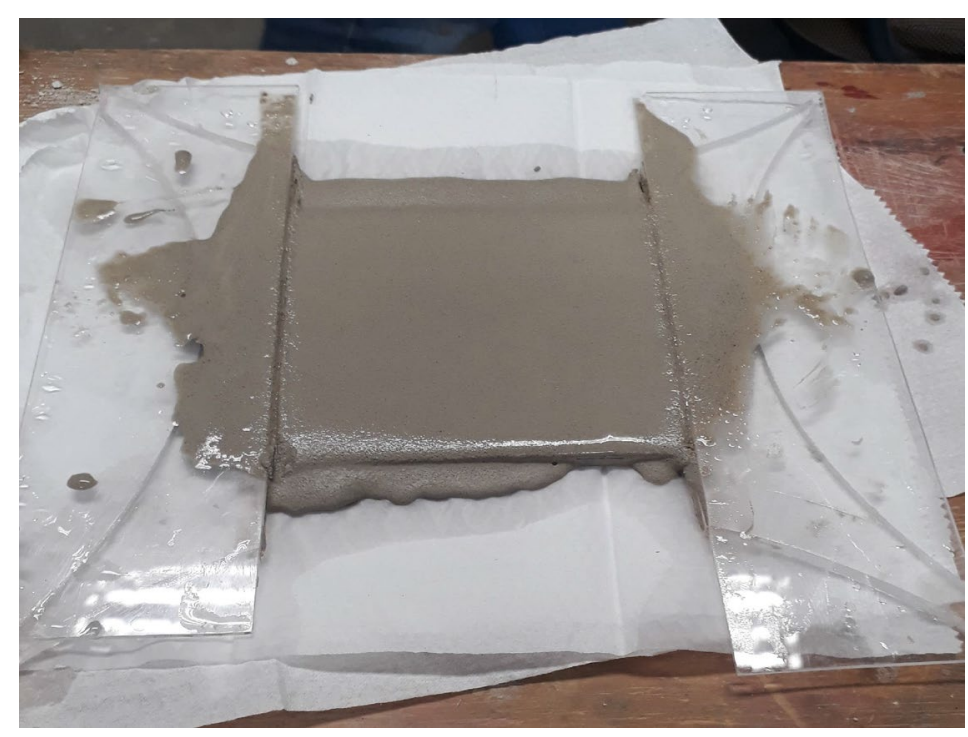

Figura 1: Secagem da placa de mistura gesso e barita

\subsection{Caracterização química dos materiais}

A caracterização química das placas foi realizada no Departamento de Instrumentação e Análises Ambientais do Centro Regional de Ciências Nucleares do Nordeste - DIAMB/CRCN-NE, utilizando o Espectrômetro de Fluorescência de Raios X por dispersão de energia (EDXRF.

$\mathrm{Na}$ caracterização química foram feitas as leituras para as placas de gesso e da mistura gesso e barita, como também dos pós de gesso e barita que constituíram as placas em si. As placas precisaram ser fragmentadas manualmente e após isso, os fragmentos foram condiminuidos no almofariz por um pistilo, conforme Figura 2. Após as placas passarem pelo processo de moagem manual, o pó resultante delas passou por um sistema artesanal de peneira (Figura 3) até atingir a dimensão apropriada para leitura no EDXRF, que deve ser menor que 80 micrômetros. O processo de peneiramento também foi feito para os pós de gesso e barita. 


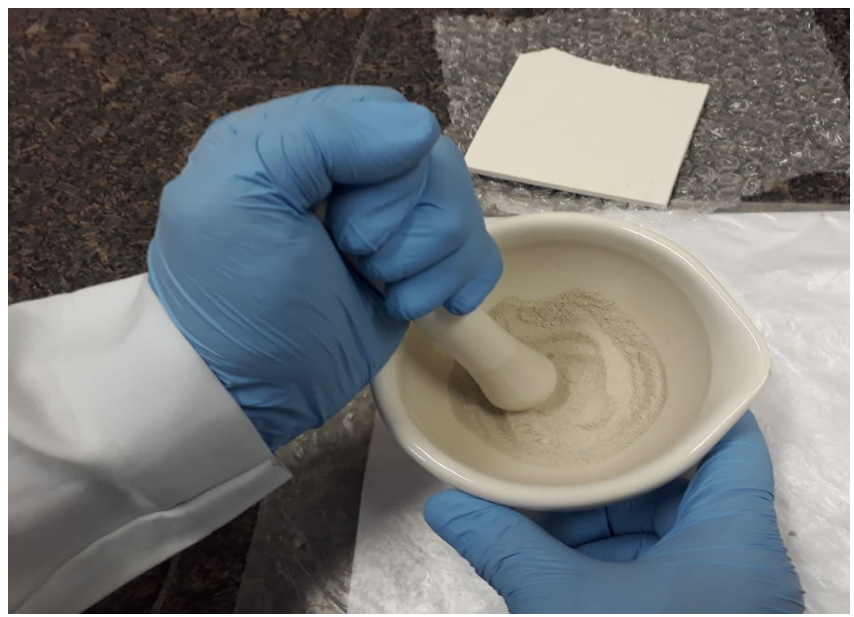

Figura 2: Moagem de placa

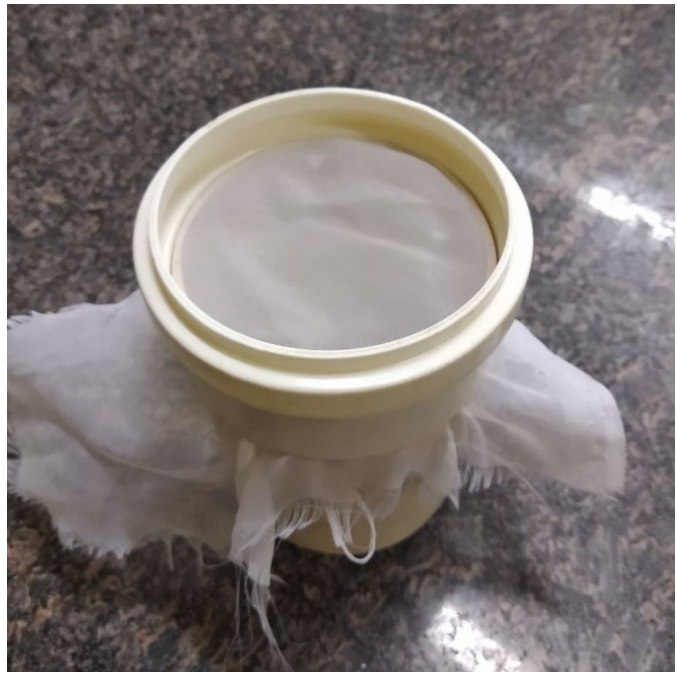

Figura 3: Peneira

Uma vez pulverizadas, as amostras foram pesadas em balança de precisão analítica sob papel seda, a fim de se evitar perda do material amostral. Logo após pesadas, estas amostras foram transferidas para recipientes de polietileno (próprios para correta leitura no EDXRF) em quantidades suficientes para cobrir a superfície de leitura dos referidos recipientes. Estes recipientes são lacrados com filme de polipropileno e anel de polietileno de acordo com as Figuras 4 e 5. 


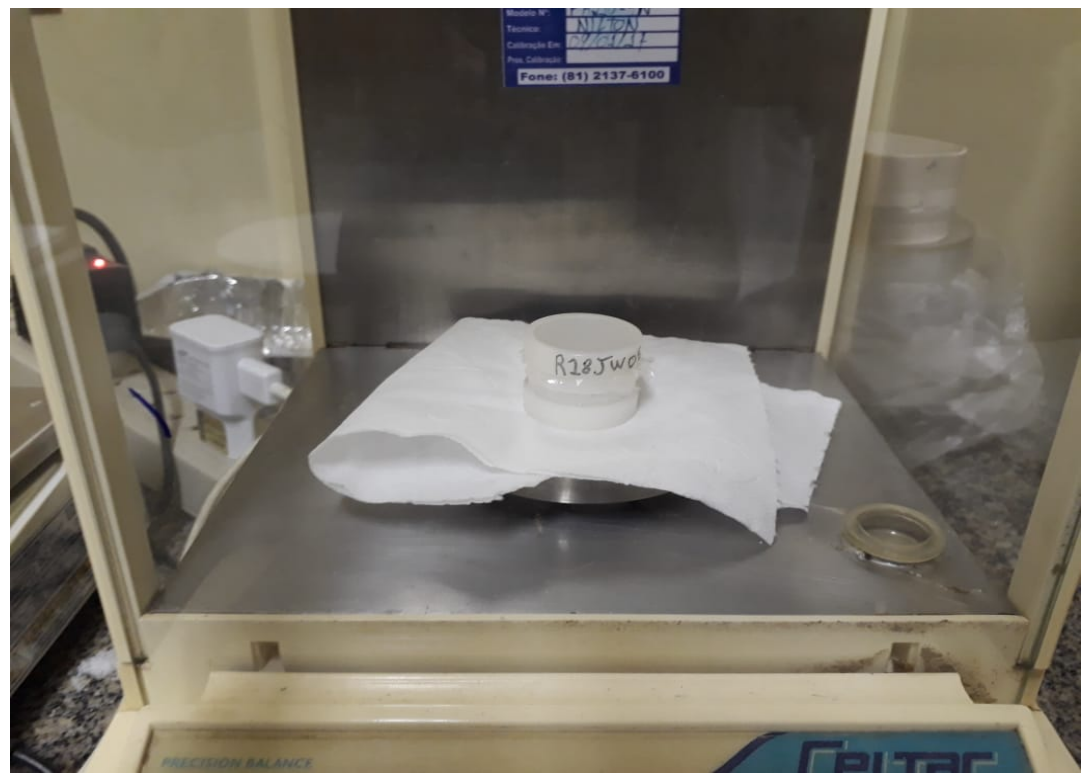

Figura 4: Amostras em recipientes lacrados

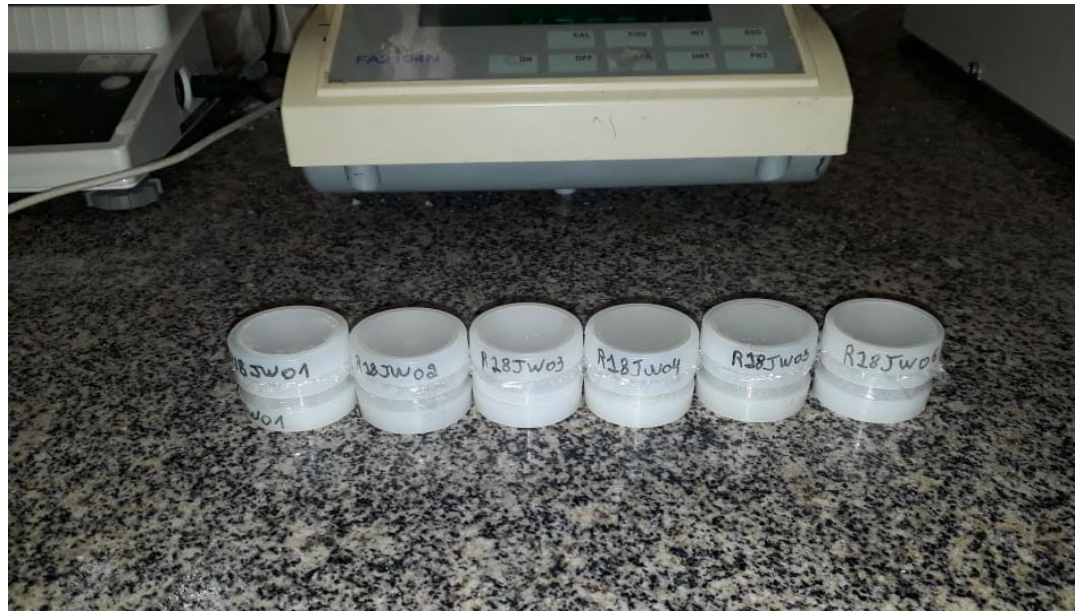

Figura 5: Pesagem de amostra.

Dessa forma, após lacrados os receptáculos contendo as amostras, os mesmos foram postos num desumidificador até a análise. Para a análise em questão, foram escolhidos materiais de referência apropriados ao tipo de material analisado para serem lidos juntos no equipamento de marca/modelo: Shimadzu Europe/EDX-720 (Figura 6). Após análise foi gerado um relatório quali-quantitativo ao qual caracterizou quimicamente as amostras. 


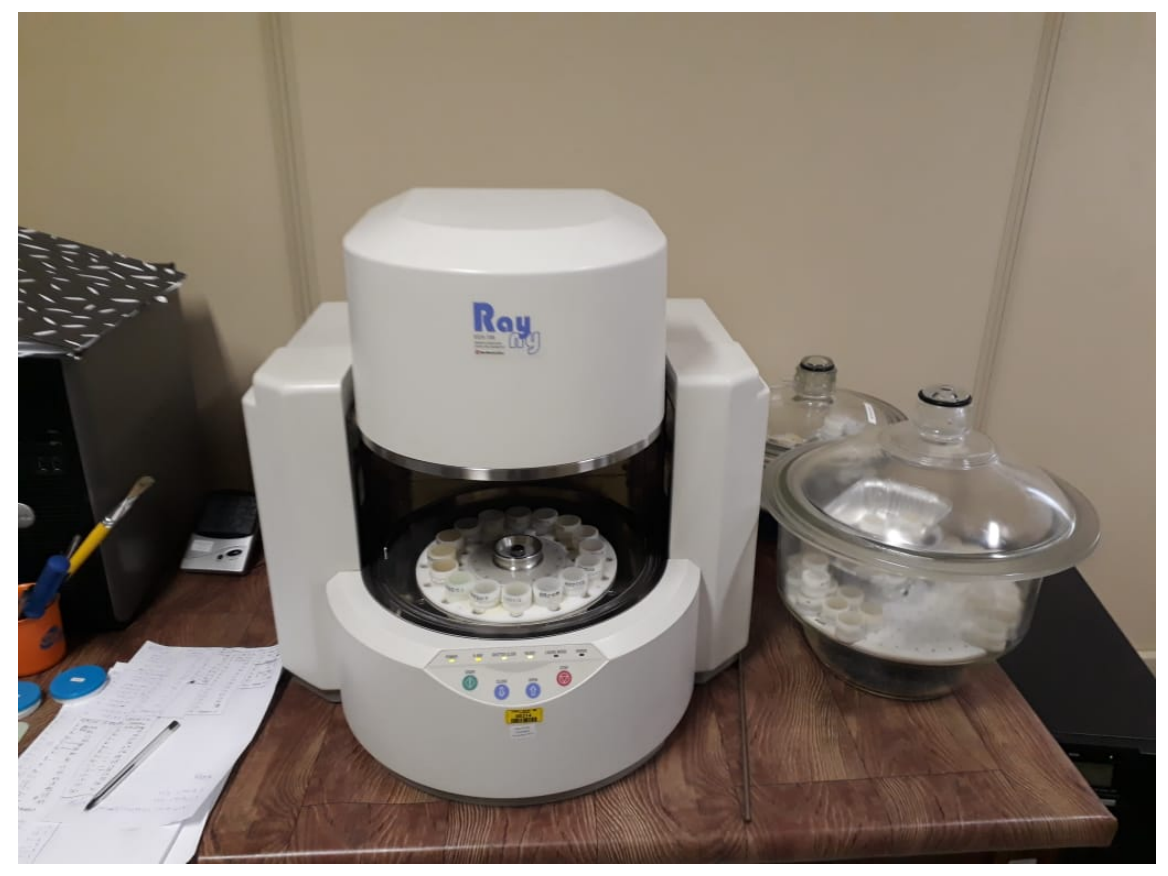

Figura 6: Leitura de amostras no EDXRF

\subsection{Irradiação das placas de gesso e da mistura gesso e barita em laboratório de Metrologia}

A obtenção das curvas de transmissão, tanto quanto dos espectros das placas de gesso e da mistura gesso e barita foram realizadas no Laboratório de Metrologia das Radiações Ionizantes do Departamento de Energia Nuclear da Universidade Federal de Pernambuco (LMRI - DEN/UFPE). Foi usada a qualidade de referência WMV (feixe de mamografia), seguindo os padrões internacionais do Physikalisch-Technische Bundesanstalt (PTB), conforme Tabela 1.

Tabela 1: Qualidades dos feixes de mamografia (WMV) implantados no LMRI-DEN/UFPE.

\begin{tabular}{cccc}
\hline $\begin{array}{c}\text { Qualidade } \\
\text { da }\end{array}$ & $\begin{array}{c}\text { Tensão no } \\
\text { tubo }(\mathrm{kV})\end{array}$ & $\begin{array}{c}\text { Corrente no } \\
\text { tubo }(\mathrm{mA})\end{array}$ & $\begin{array}{c}\text { Filtração adicional } \\
(\mathrm{mmMo})^{1}\end{array}$ \\
\hline Radiação & 28 & 10 & 0,06 \\
WMV28 & 35 & 10 & 0,06 \\
\hline
\end{tabular}


As irradiações das placas de gesso e as placas de mistura gesso e barita foram realizadas primeiramente para a avaliação das diferenças no poder de blindagem de cada uma. $\mathrm{O}$ esquema do arrranjo das irradiações das placas pode ser visto na Figura 7. A câmara de ionização específica para mamografia utilizada foi a de marca PTW Freiburg, modelo TN34069. A mesma têm baixa dependência energética, inferior a 2\% na faixa de energia utilizada (PTW, 2016).

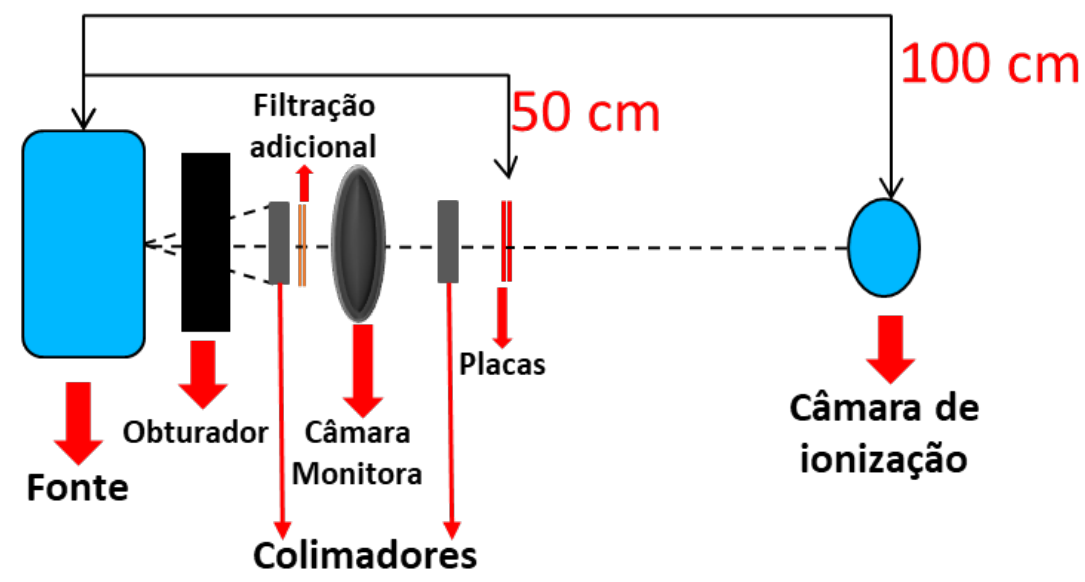

Figura 7: Esquema do arranjo experimental em condições de boa geometria no LMRI-

\section{$D E N / U F P E$}

Para compor a curva de transmissão para as placas de gesso e barita, foram utilizados 11 pontos correspondentes às espessuras que variavam de 1,918 $\mathrm{mm}$ até 16,238 $\mathrm{mm}$. Já para as placas de gesso, foram feitas 11 medições de diferentes espessuras variando entre 2,578 mm e 16,354 mm. Lembrando que antes de qualquer irradiação, sempre eram feitas as medidas sem blindagem alguma entre a fonte e o detector, de modo a saber-se a intensidade inicial ( $\left.\mathrm{I}_{0}\right)$. As Tabela 2 e 3 mostram as espessuras de cada tipo de placa, bem como as combinações usadas durante as irradiações experimentais. 
Tabela 2: Espessuras das placas de mistura gesso e barita utilizados no ensaio e suas combinações.

\begin{tabular}{cl}
\hline Espessuras $(\mathbf{m m})$ & \multicolumn{1}{c}{ Combinações $(\mathbf{m m})$} \\
\hline 0,918 & 1 Placa $(0,918)$ \\
2,326 & 1 Placa $(2,326)$ \\
3,041 & 1 Placa $(3,041)$ \\
4,772 & 1 Placa $(4,772)$ \\
5,615 & 1 Placa $(5,615)$ \\
7,533 & 2 Placas $(1,918+5,615)$ \\
9,675 & 3 Placas $(1,918+2,142+5,062)$ \\
11,217 & 2 Placas $(5,162+5,602)$ \\
13,135 & 3 Placas $(1,918+5,162+5,602)$ \\
16,238 & 3 Placas $(5,020+5,162+5,602)$
\end{tabular}

Tabela 3: Espessuras das placas de gesso utilizadas no ensaio e suas combinações.

\begin{tabular}{cl}
\hline Espessuras (mm) & \multicolumn{1}{c}{ Combinações $(\mathbf{m m})$} \\
\hline 2,578 & 1 Placa $(2,578)$ \\
2,740 & 1 Placa $(2,740)$ \\
5,242 & 1 Placa $(5,242)$ \\
5,482 & 1 Placa $(5,482)$ \\
7,820 & 2 Placas $(2,578+5,242)$ \\
8,222 & 2 Placas $(2,740+5,482)$ \\
8,534 & 1 Placa $(8,534)$ \\
11,112 & 2 Placas $(2,578+8,534)$ \\
13,776 & 2 Placas $(5,242+8,534)$ \\
16,354 & 3 Placas $(2,578+5,242+8,534)$ \\
\hline
\end{tabular}

Os espectros de raios $\mathrm{X}$ foram medidos através de um semicondutor de CdTe. Para a montagem do arranjo foi necessário o auxílio de dois lasers, sendo um lateralmente e o outro por trás, para o correto posicionamento do detector CdTe (Figura 8) 


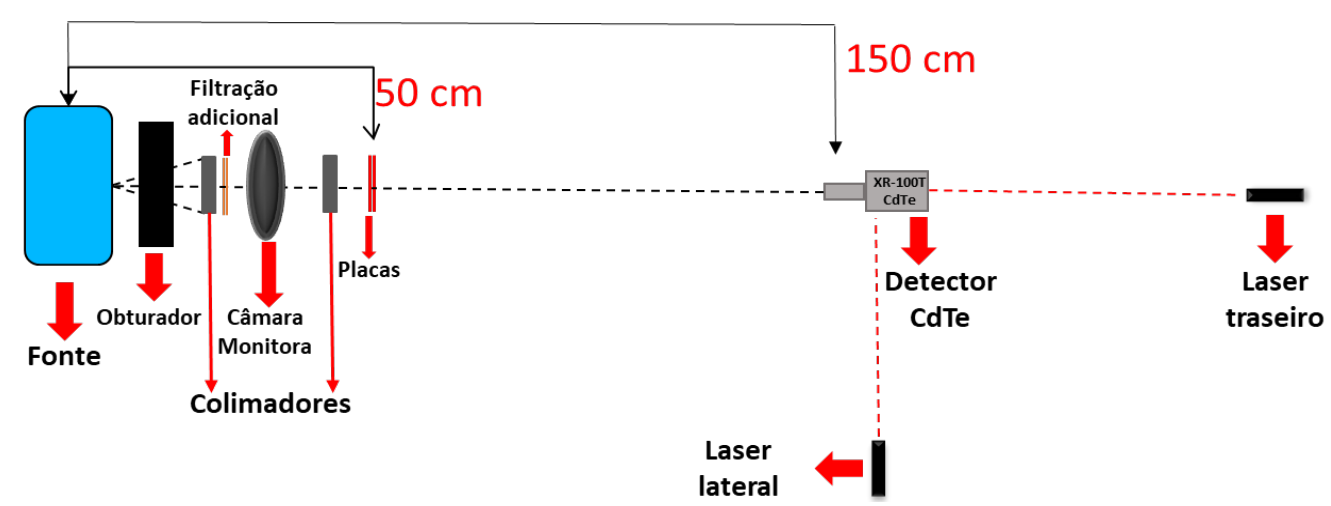

Figura 8: Esquema do arranjo experimental em condições de boa geometria no LMRIDEN/UFPE.

\section{RESULTADOS E DISCUSSÃO}

Os resultados alcançados neste trabalho estão descritos e separados por tópicos de acordo com as etapas realizadas e metodologias aplicadas, que são: Caracterização física e química das placas de gesso e as placas de mistura gesso e barita, as curvas de transmissão, CSR, CDR e espectros obtidos a partir das placas já citadas, de acordo com as qualidades WMV.

\subsection{Caracterização física e química das placas de gesso e da mistura gesso e barita}

Apesar de todo cuidado e controle na hora da construção das placas de gesso, as mesmas foram feitas de modo artesanal. Por mais que tenham sido utilizados moldes de acrílico com espessuras distintas de 2,5 mm, 5,0 mm e 8,00 mm, as placas ainda sim saíram com pequenas variações de tamanho e espessura entre elas. Portanto as densidades e espessuras de cada placa de gesso variam entre si, como visto na Tabela 4. 
Tabela 4: Caracterização física das placas de gesso.

\begin{tabular}{cccc}
\hline Espessura (mm) & Massa (g) & $\begin{array}{c}\text { Volume } \\
\left(\mathbf{c m}^{\mathbf{3}}\right)\end{array}$ & $\begin{array}{c}\text { Densidade } \\
\mathbf{( g / \mathbf { c m } ^ { 3 } )}\end{array}$ \\
\hline 2,578 & 28,85 & 25,04 & 1,15 \\
2,740 & 29,64 & 26,17 & 1,13 \\
5,242 & 63,08 & 52,14 & 1,21 \\
5,482 & 65,14 & 56,10 & 1,16 \\
8,188 & 98,12 & 81,75 & 1,20 \\
8,336 & 100,91 & 83,50 & 1,21 \\
8,533 & 103,61 & 86,02 & 1,20 \\
\hline
\end{tabular}

A Tabela 5 mostra os detalhes da caracterização das placas de mistura gesso e barita. Foram feitas 12 placas de mistura de gesso e barita, mas nem todas foram usadas também durante o experimento de irradiação. Para o material misturado é nítido o aumento da densidade se comparado com as placas de gesso puro, isso se dá devido ao incremento de um material mais denso que o gesso, no caso a barita. A variação entre as densidades ficou em 7,40\%, sendo o menor e o maior valor, respectivamente, 1,64 e $1,77 \mathrm{~g} / \mathrm{cm} 3$.

Tabela 5: Caracterização física das placas de mistura gesso e barita.

\begin{tabular}{|c|c|c|c|}
\hline $\begin{array}{c}\text { Espessura } \\
(\mathrm{mm})\end{array}$ & Massa (g) & $\begin{array}{c}\text { Volume } \\
\left(\mathrm{cm}^{3}\right)\end{array}$ & $\begin{array}{c}\text { Densidade } \\
\left(\mathrm{g} / \mathrm{cm}^{3}\right)\end{array}$ \\
\hline 1,918 & 31,44 & 18,21 & 1,727 \\
\hline 2,142 & 34,07 & 20,77 & 1,640 \\
\hline 2,219 & 36,44 & 21,41 & 1,702 \\
\hline 2,327 & 37,74 & 22,71 & 1,662 \\
\hline 2,483 & 40,93 & 24,72 & 1,656 \\
\hline 3,041 & 41,99 & 29,26 & 1,708 \\
\hline 4,773 & 81,35 & 45,99 & 1,769 \\
\hline 5,021 & 83,42 & 48,04 & 1,736 \\
\hline 5,143 & 84,49 & 48,63 & 1,737 \\
\hline 5,162 & 86,74 & 48,98 & 1,771 \\
\hline 5,393 & 89,76 & 50,85 & 1,765 \\
\hline 5,603 & 92,52 & 54,65 & 1,693 \\
\hline
\end{tabular}


A análise para o pó de gesso ao qual foi utilizado para se fazer as placas (Tabela 6), contém uma concentração com cerca de $99 \%$ de Sulfato de Cálcio $\left(\mathrm{CaSO}_{4}\right)$ da composição total. Enquanto menos de $1 \%$ encontrado é de impurezas como: Óxido de Potássio $\left(\mathrm{K}_{2} \mathrm{O}\right)$, Óxido de Estrôncio ( $\mathrm{SrO})$, Óxido de Fósforo $\left(\mathrm{P}_{2} \mathrm{O}_{5}\right)$, Óxido de Ferro $\left(\mathrm{Fe}_{2} \mathrm{O}_{3}\right)$, Dióxido de Zircônio $\left(\mathrm{ZrO}_{2}\right)$.

Tabela 6: Análise do pó de gesso.

\begin{tabular}{cc}
\hline Análise & $\begin{array}{c}\text { Resultados } \\
(\%)\end{array}$ \\
\hline $\mathrm{SO}_{3}$ & 68,792 \\
$\mathrm{CaO}$ & 30,787 \\
$\mathrm{~K}_{2} \mathrm{O}$ & 0,224 \\
$\mathrm{SrO}$ & 0,106 \\
$\mathrm{P}_{2} \mathrm{O}_{5}$ & 0,057 \\
$\mathrm{Fe}_{2} \mathrm{O}_{3}$ & 0,031 \\
$\mathrm{ZrO}_{2}$ & 0,003 \\
\hline
\end{tabular}

Fonte: Arquivo da análise no EDXRF (Adaptado).

Para o gesso as impurezas contidas na matéria prima podem afetar o tempo de pega, acelerando-a por atuarem como núcleos de cristalização. Desta forma, torna-se fundamental determinar a sua pureza. No entanto, diante das frações mássicas atribuídas as impurezas presentes, pode-se observar a elevada pureza do material [2].

A análise do pó de barita ao qual faz parte da mistura da placa de gesso e barita, pode ser visto na Tabela 7.

Tabela 7: Análise do pó de barita.

\begin{tabular}{cc}
\hline Análise & $\begin{array}{c}\text { Resultados } \\
(\%)\end{array}$ \\
\hline $\mathrm{BaO}$ & 33,745 \\
$\mathrm{SO}_{3}$ & 30,640 \\
$\mathrm{SiO}_{2}$ & 29,581 \\
$\mathrm{CeO}_{2}$ & 2,034 \\
$\mathrm{Al}_{2} \mathrm{O}_{3}$ & 1,087 \\
$\mathrm{CaO}$ & 0,783 \\
$\mathrm{Fe}_{2} \mathrm{O}_{3}$ & 0,628 \\
$\mathrm{SrO}$ & 0,585 \\
$\mathrm{~K}_{2} \mathrm{O}$ & 0,170 \\
$\mathrm{ZrO}_{2}$ & 0,026 \\
\hline
\end{tabular}


O Sulfato de bário $\left(\mathrm{BaSO}_{4}\right)$ tem uma concentração com cerca de $64 \%$ da amostra total, logo após com um pouco mais que $29 \%$ é listado o Dióxido de silício $\left(\mathrm{SiO}_{2}\right)$, que é areia. Um adendo sobre a areia, a mesma já veio misturada com a argamassa baritada, ou seja, faz parte da composição do material usado, por isso já era esperado esse total de concentração, não sendo considerado contaminação, mas sim um aditivo. Também era esperado encontrar o Dióxido de Cério $\left(\mathrm{CeO}_{2}\right)$, pois o mesmo é encontrado em areias monazíticas. Óxido de Alumínio $\left(\mathrm{Al}_{2} \mathrm{O}_{3}\right)$, Óxido de Ferro $\left(\mathrm{Fe}_{2} \mathrm{O}_{3}\right)$, Óxido de Cálcio $(\mathrm{CaO})$, e Dióxido de Zircônio $\left(\mathrm{ZrO}_{2}\right)$ eram esperados que aparecessem na leitura, principalmente os dois primeiros, pois estão associados ao Cério. O Óxido de Potássio $\left(\mathrm{K}_{2} \mathrm{O}\right)$ e Óxido de Estrôncio $(\mathrm{SrO})$ podem ser considerados impurezas.

\subsection{Espectrometria das placas de gesso e da mistura gesso e barita}

Da Figura 9 a 12, é mostrado o comportamento na forma dos espectros desde a atenuação dos feixes de raios $\mathrm{X}$ apenas com a filtração adicional de Mo (sem placa) e com a colocação das placas de gesso e mistura gesso e barita. Vale lembrar que a filtração adicional de Mo é que dá ao espectro a característica de raios X mamográficos, sendo utilizadas as qualidades WMV 28 e WMV 35.

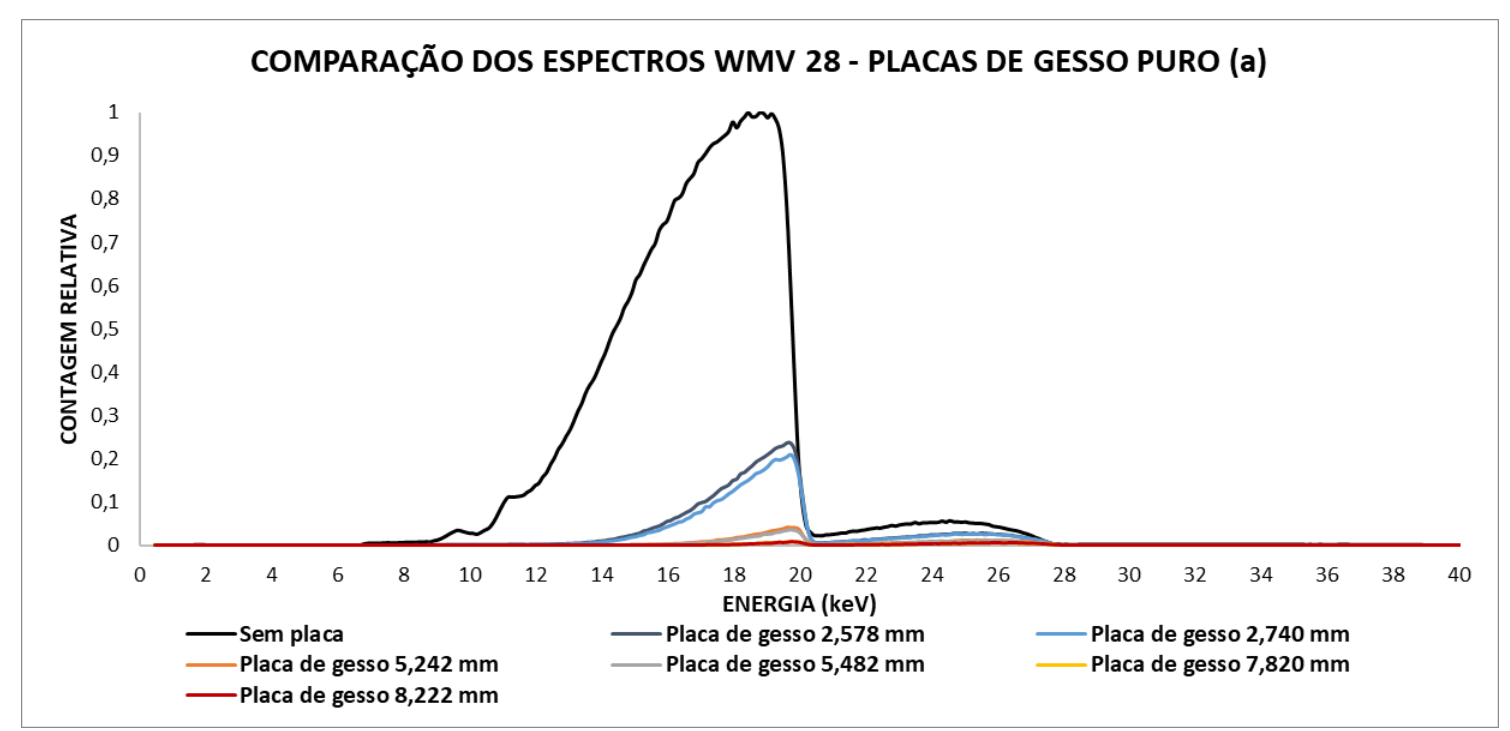

. Figura 9: Comparação de espectros na qualidade WMV 28 - Placas de gesso 
A Figura 9 mostra o espectro na qualidade WMV 28 com a utilização da placa de gesso com diferentes espessuras para atenuação do feixe de raios $\mathrm{X}$ até $28 \mathrm{keV}$. Já para a Figura 10 é possível ver o uso das placas de mistura gesso e barita para a qualidade WMV 28.

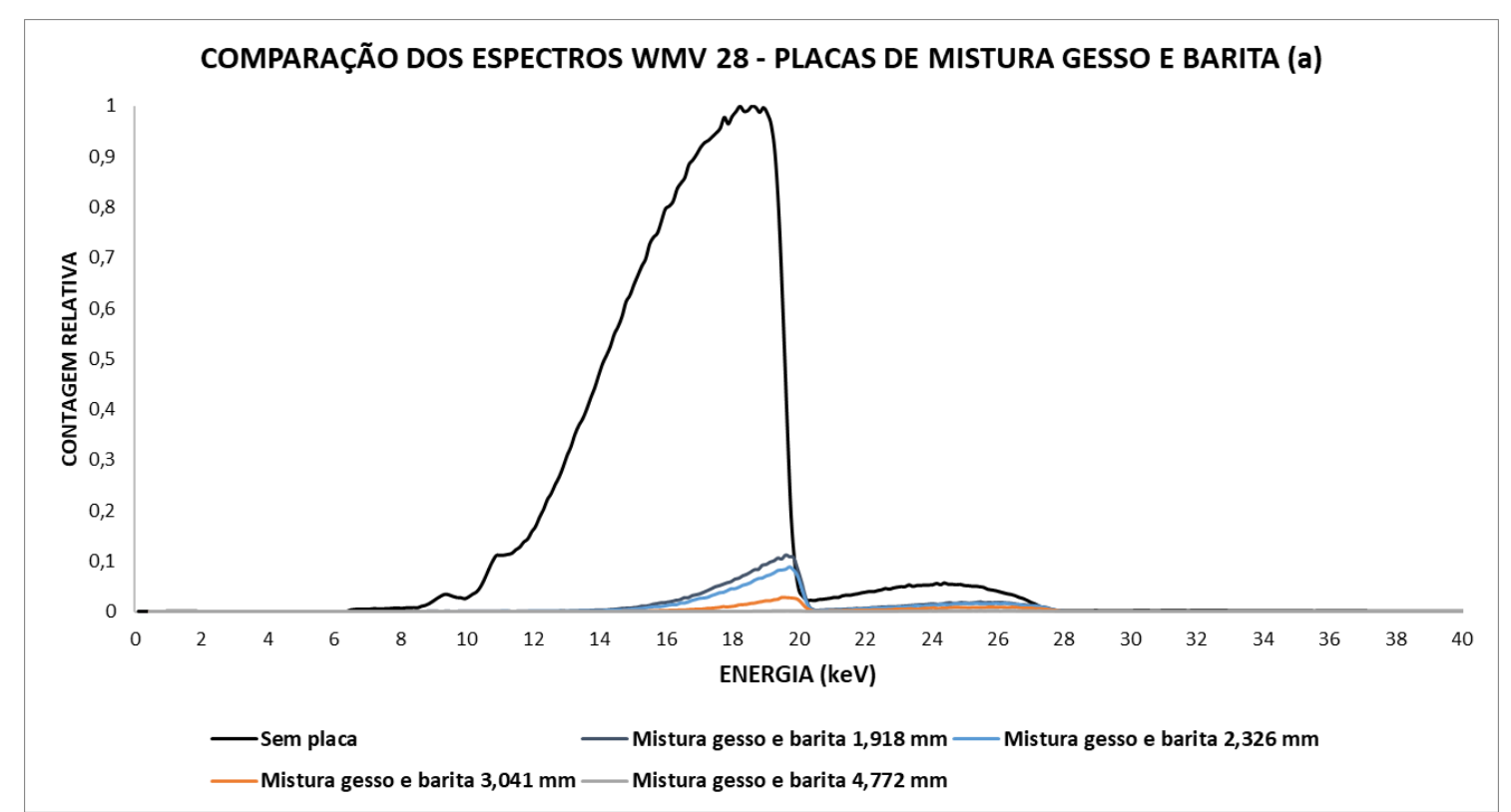

Figura 10: Comparação de espectros na qualidade WMV 28 - Placas de mistura gesso e barita.

É fácil notar a diferença quando comparados os espectros das placas de gesso e mistura gesso barita, ainda que se mantendo os mesmos parâmetros de irradiação para ambas. Ainda que as placas de gesso atenuem muito bem os fótons de raios $\mathrm{X}$ com até $28 \mathrm{keV}$, as placas de mistura gesso e barita fazem esse trabalho ainda melhor e isso se deve a diferença entre as suas densidades.

Para uma melhor análise e entendimento dos resultados, na Tabela 8 é visto o número total de contagens de fótons de raios $\mathrm{X}$ levando em conta todo o espectro para cada tipo de placa e suas diferentes espessuras na qualidade WMV 28. 
Tabela 8: Número total de fótons de raios X em diferentes placas - WMV 28.

\begin{tabular}{ccc}
\hline Tipo de placa & Espessura $(\mathbf{m m})$ & $\begin{array}{c}\mathbf{N}^{\mathbf{0}} \text { total de fótons } \\
\text { de raios X }\end{array}$ \\
\hline $\begin{array}{c}\text { Sem placa (apenas } \\
\text { filtro de Mo) }\end{array}$ & 0 & 2.299 .562 \\
Gesso puro & 2,578 & 328.991 \\
Gesso puro & 2,740 & 283.696 \\
Gesso puro & 5,242 & 55.310 \\
Gesso puro & 5,482 & 48.372 \\
Gesso puro & 7,820 & 14.878 \\
Gesso puro & 8,222 & 13.013 \\
Mistura gesso e barita & 1,918 & 150.453 \\
Mistura gesso e barita & 2,326 & 144.055 \\
Mistura gesso e barita & 3,041 & 39.747 \\
Mistura gesso e barita & 4,772 & 5.932 \\
\hline
\end{tabular}

Fonte: $\mathrm{O}$ autor.

A Tabela 8 apresenta a redução dos fótons em relação a espessura das placas. Nas placas de gesso, a redução vista é bastante considerável, porém a eficácia e capacidade de atenuação das placas de mistura gesso e barita é visivelmente maior.

As Figuras 11 e 12 mostram a comparação dos espectros na qualidade WMV 35 para os dois tipos de placa acima mencionados.

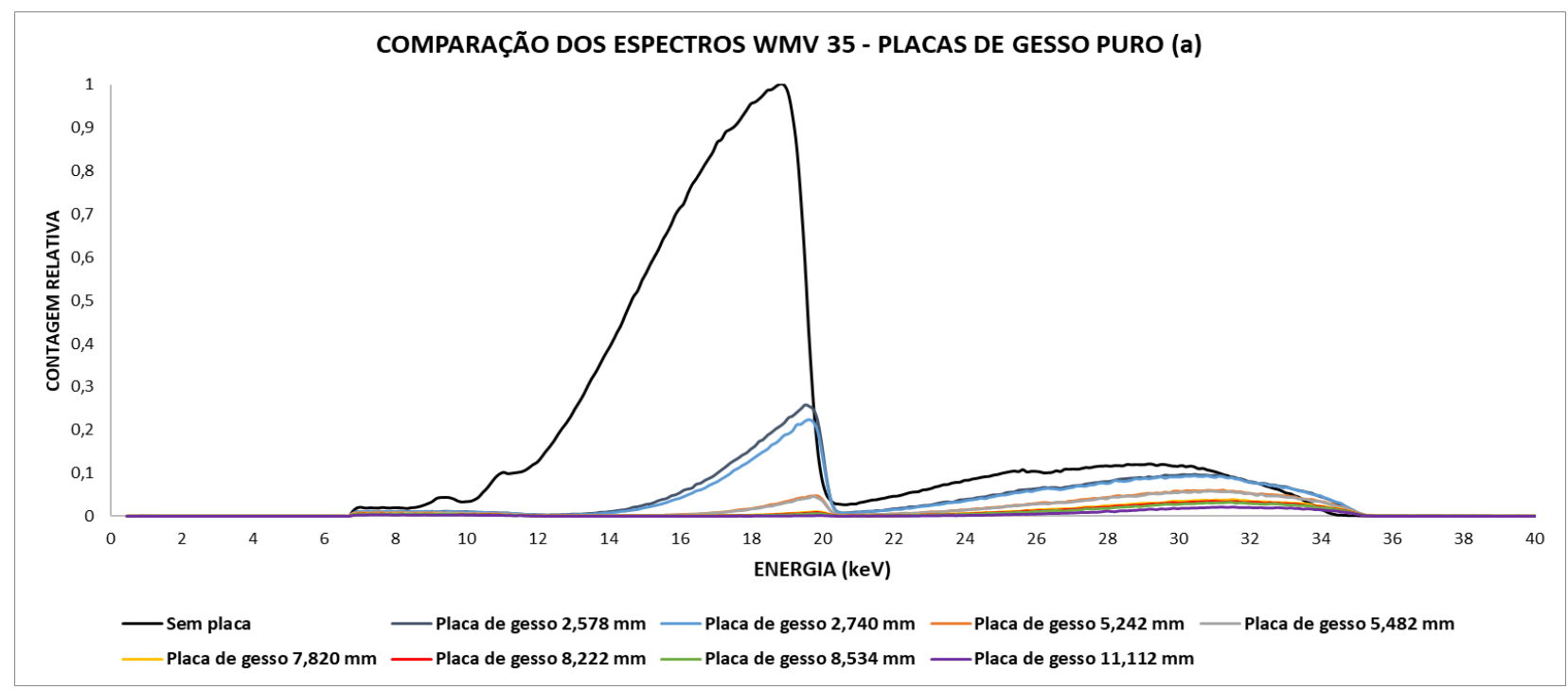

Figura 11: Comparação de espectros na qualidade WMV 35 - Placas de gesso 


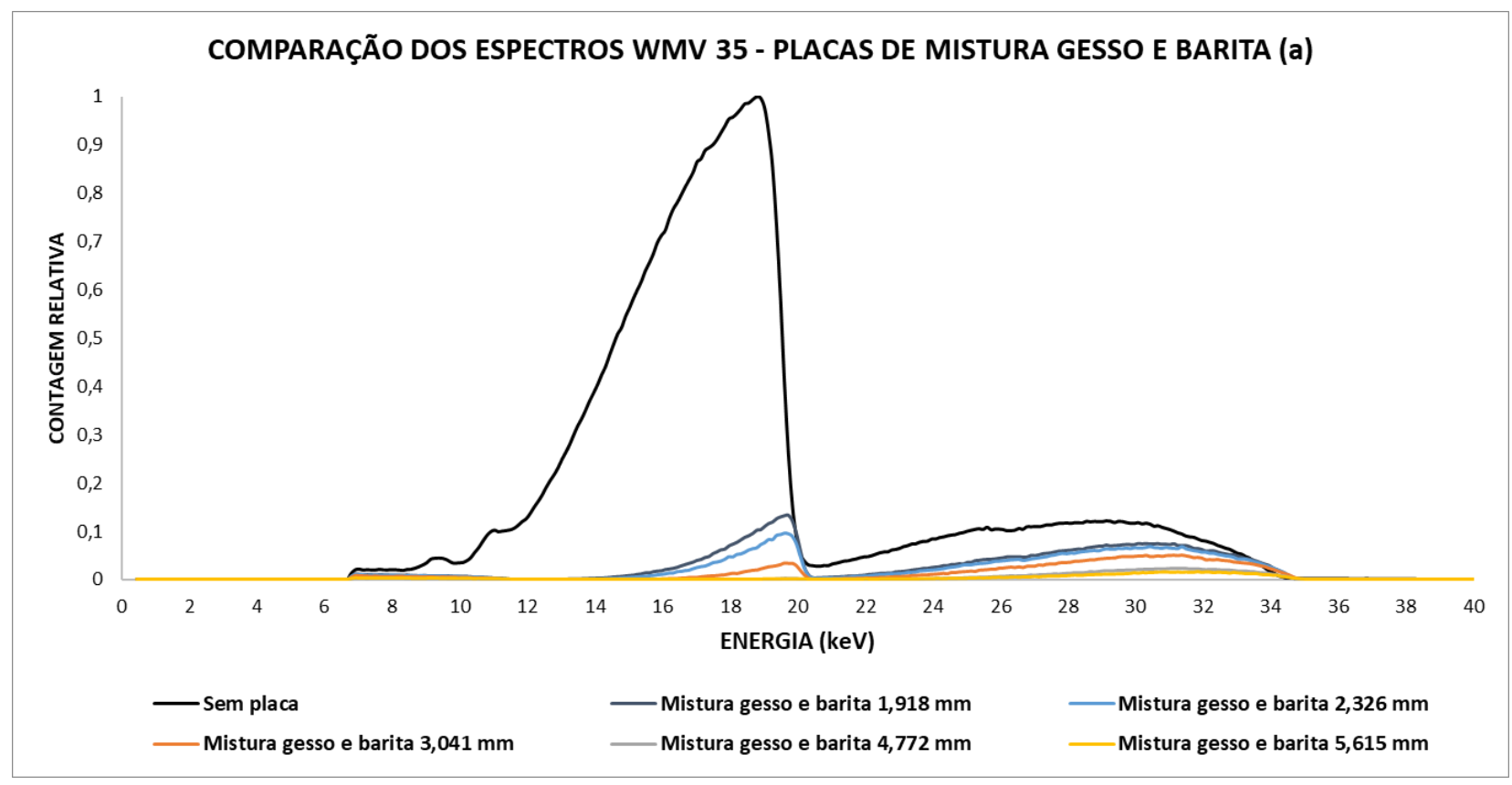

Figura 12: Comparação de espectros na qualidade WMV 35 - Placas de mistura gesso e barita.

Assim como na Tabela 8, na Tabela 9 é visto o número total de contagens de fótons de raios $\mathrm{X}$ levando em conta todo o espectro para cada tipo de placa e suas diferentes espessuras na qualidade WMV 35.

\subsection{Curvas de transmissão para as placas de gesso e da mistura gesso e barita}

As curvas de transmissão foram feitas a partir da relação dos valores da corrente sem nenhuma blindagem e dos valores das correntes obtidas durante a irradiação das placas que serviam como barreira contra a radiação e diminuíam a sua intensidade $\left(\mathrm{I} / \mathrm{I}_{0}\right)$.

Nas Figuras 13 e 14, têm-se as comparações entre as curvas de transmissão para as qualidades WMV28 e WMV35 de acordo com o tipo de placa utilizado.

Tanto a Tabela 8, quanto a Tabela 9, assim como das Figuras 9 a 12, é mostrado claramente que as placas de mistura gesso e barita tem uma eficiência de blindagem maior e melhor quando comparadas as placas de gesso puro, seja para a qualidade WMV 28 ou WMV 35. 
Tabela 9: Número total de fótons de raios X em diferentes placas - WMV 35.

\begin{tabular}{|c|c|c|}
\hline Tipo de placa & Espessura (mm) & $\begin{array}{l}N^{0} \text { total de fótons } \\
\text { de raios } X\end{array}$ \\
\hline $\begin{array}{l}\text { Sem placa (apenas } \\
\text { filtro de Mo) }\end{array}$ & 0 & 3.645 .353 \\
\hline Gesso puro & 2,578 & 930.170 \\
\hline Gesso puro & 2,740 & 841.888 \\
\hline Gesso puro & 5,242 & 345.947 \\
\hline Gesso puro & 5,482 & 334.991 \\
\hline Gesso puro & 7,820 & 181.782 \\
\hline Gesso puro & 8,222 & 167.968 \\
\hline Gesso puro & 8,534 & 150.715 \\
\hline Gesso puro & 11,112 & 90.873 \\
\hline Mistura gesso e barita & 1,918 & 563.525 \\
\hline Mistura gesso e barita & 2,326 & 457.686 \\
\hline Mistura gesso e barita & 3,041 & 269.311 \\
\hline Mistura gesso e barita & 4,772 & 106.184 \\
\hline Mistura gesso e barita & 5,615 & 61.741 \\
\hline
\end{tabular}

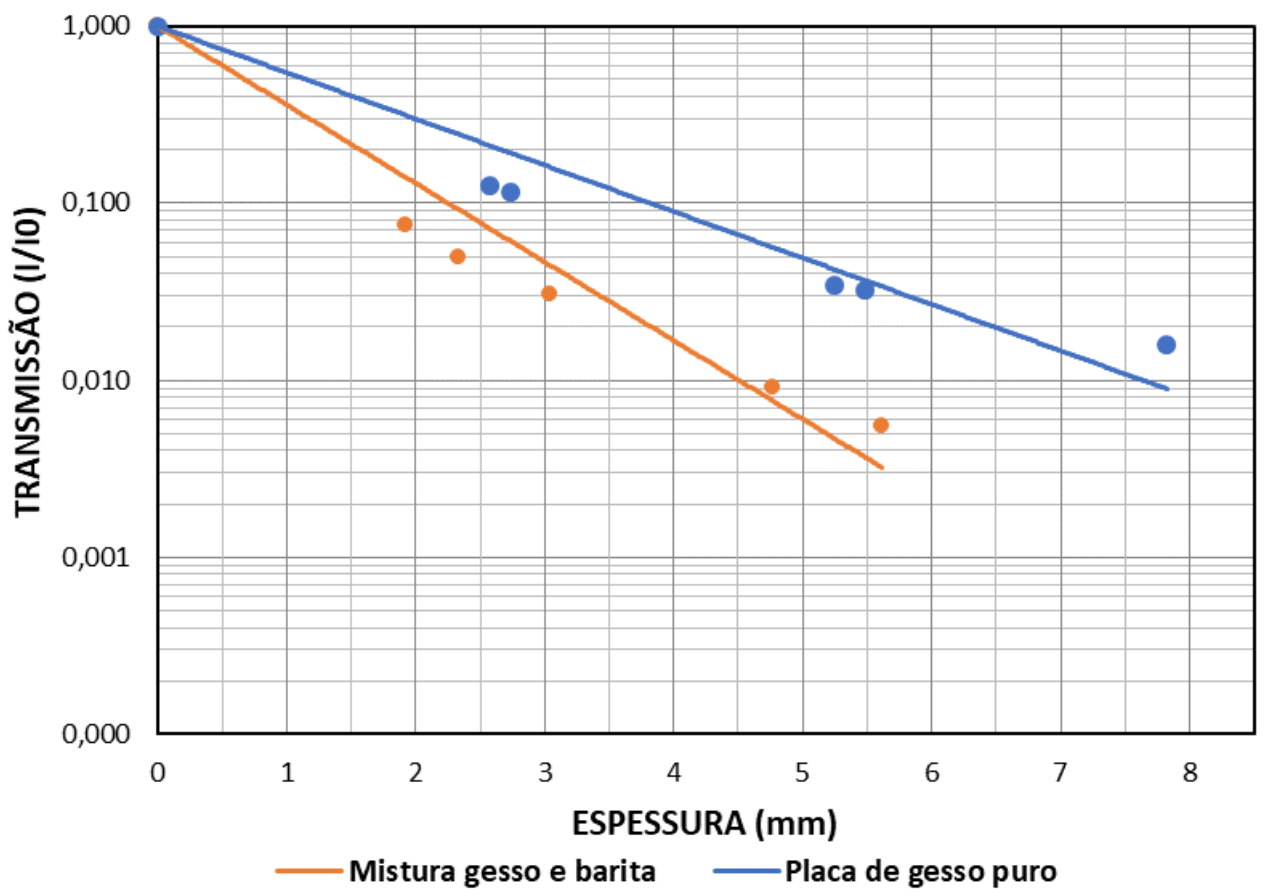

Figura 13: Comparação das curvas de transmissão para WMV28. 


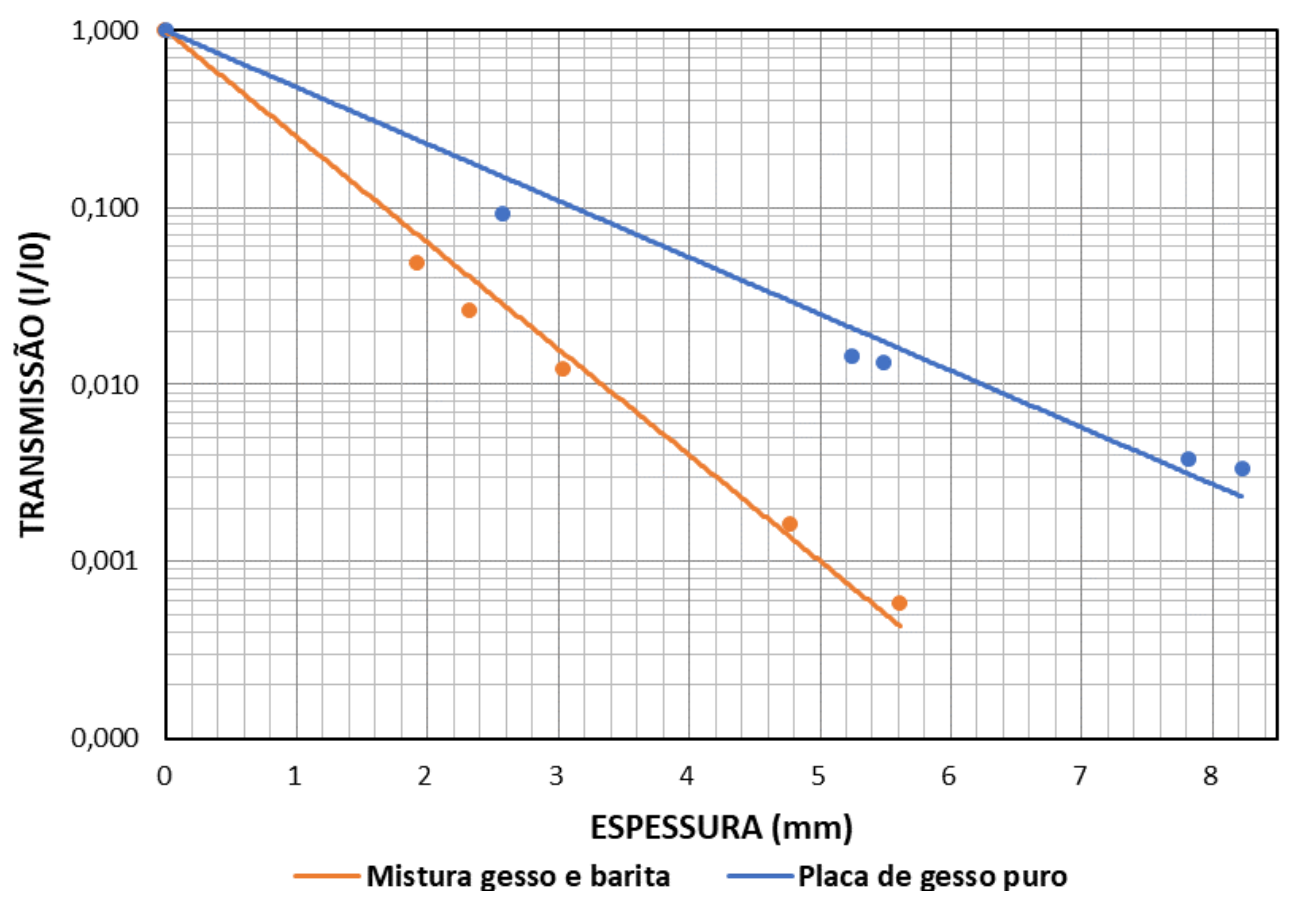

Figura 14: Comparação das curvas de transmissão para WMV35.

Nas duas comparações das curvas de transmissão, é possível notar que as placas de mistura gesso e barita possuem um maior poder de atenuação dos fótons de raios $\mathrm{X}$ se comparado com as placas de gesso puro com granulometria do fabricante. Este tipo de resposta já era esperado, visto que as placas de mistura têm barita em sua composição e esta é mais densa que o gesso em si. Na Tabela 10 pode ser visualizado as CSR e CDR para os dois tipos de placa em relação as qualidades utilizadas.

Tabela 10: CSR e CDR das placas de gesso e mistura gesso barita nas qualidades WMV.

\begin{tabular}{cccc}
\hline Qualidade & Tipo de placa & CSR $(\mathbf{m m})$ & CDR $(\mathbf{m m})$ \\
\hline WMV28 & Gran. Fabricante & 0,848 & 2,818 \\
WMV28 & Mistura gesso e barita & 0,501 & 1,667 \\
WMV35 & Gran. Fabricante & 1,149 & 3,818 \\
WMV35 & Mistura gesso e barita & 0,678 & 2,253 \\
\hline
\end{tabular}

As CSR e CDR mostram a superioridade da blindagem das placas de mistura gesso e barita em relação as placas de gesso puro, sendo tanto para as qualidades WMV28 quanto para WMV35. Este tipo de resposta comprova o que já era previsto, a eficácia do gesso quando misturado com a barita 
é maior do que a do material gesso puro, pois a sua densidade é superior, tornando-o assim um melhor atenuador.

\section{CONCLUSÕES}

De um modo geral, é certo dizer que a mistura do material gesso e barita é uma blindagem mais eficaz quando comparado as placas de gesso puro, devido a sua maior densidade. Esse tipo de mistura dá uma nova luz àqueles que querem unir em uma só blindagem: bom material atenuador para baixas energias, baixo custo financeiro, facilidade na confecção destes tipos de placas misturadas e possível estética do ambiente. Entretanto, apesar da mistura gesso e barita possuir uma maior eficiência, as placas de gesso puro não devem ser descartadas como blindagens para baixas energias, já que a mesma possui todas as mesmas características já descritas acima para as placas de gesso e barita misturadas. Além do mais, é economicamente mais viável e a espessura de sua $\operatorname{CDR}(3,818 \mathrm{~mm})$ é menor do que a espessura de um bloco de gesso vendido comercialmente $(70 \mathrm{~mm})$, denotando uma melhor relação custo/benefício em processos e otimização da proteção radiológica.

\section{REFERÊNCIAS}

[1] GONDIM, P. C. A. Desenvolvimento de bloco de vedação com barita da composição de partida para blindagem. Tese (Doutorado) - Universidade do Rio Grande do Norte. Centro de Ciências Exatas e da Terra. Programa de Pós-Graduação em Ciência e Engenharia de Materiais. Natal, RN, 2009.

[2] BARbOSA, A. A.; FERrAZ, A. V.; SANTOS, G. A. Caracterização química, mecânica e morfológica do gesso obtido do pólo do Araripe. Revista Cerâmica, São Paulo, v. 60, n. 356, p. 501-508, dez. $2014 . \quad$ Disponível em: $<$ http://www.scielo.br/scielo.php?script=sci_arttext\&pid=S036669132014000400007\&lng=pt\& nrm=iso $>$. Data de acesso: 15 de dezembro de 2018. http://dx.doi.org/10.1590/S036669132014000400007. 